\title{
VARIACIÓ ORDENADA EN SITUACIONS MULTILINGÜES. OBSERVACIÓ EN ADOLESCENTS LLEIDATANS ${ }^{1}$
}

\author{
JOSEFINA CARRERA-SABATÉ \& IMMA CREUS
}

\begin{abstract}
The aim of this paper is to analyze mid vowel segments as pronounced by a group of adolescents who speak Spanish and the Catalan variety of Lleida and whose L1 is Catalan or Roumanian. The analysis is based on a linguistic component related to the phonological contrast of both languages, Catalan and Roumanian, as well as to social and sociolinguistic variables such as gender, the length of time of residence in the welcoming country, and language usage and assessment of the participants in the pronunciation poll.

The results show differences in the production between mid vowels $[\varepsilon]$ and $[0]$ related to: 1) the degree of openness (F1) of the two segments, since vowels articulated by L1 Catalan speakers are the lowest; 2) the distance between the F1 of [e $\varepsilon$ ] and [o o], which is greater in those articulated by L1 Catalan speakers; 3) the length of the vowels, for they are usually shorter in the speech of L1 Catalan speakers. The most statistically significant variables were as follows: gender (Catalan girls present higher F1); the usage frequency of Catalan by L1 Roumanian speakers (those with the highest usage frequency articulate $[\varepsilon]$ and [0] with a higher L1, i.e. their vowels are more open); and the high levels of Catalan usage, which may also have an influence on production.
\end{abstract}

\section{INTRODUCCIÓ}

\subsection{Multilingüisme}

El multilingüisme avui és un fenomen comú a tot el món i es considera lligat bàsicament a la globalització i als processos migratoris generalitzats, de manera que la singularitat cada cop més radica a trobar societats i parlants monolingües. Més enllà de les interpretacions diverses que es poden atorgar al concepte, el multilingüisme permet un enfocament des de perspectives de recerca diferents i sovint complementàries (vegeu García-Mayo; Wei): educativa (Cenoz), lingüística (Leung), neurolingüística (Franceschini, Zappatore i Nitsc), psicolingüística (De Angelis) i sociolingüística (Hoffman i Ytsma). En l'àmbit de la recerca feta a Catalunya a l'entorn del multilingüisme Comajoan assenyala que, si ens fixem en el ressò internacional, els estudis de la perspectiva psicolingüística són els capdavanters, mentre que, si ho fem en l'impacte i l'aplicabilitat a nivell local, destacarien les recerques de tipus sociolingüístic (Comajoan, "Multilingüisme" 256). Justament en el camp de la sociolingüística, Vila ("De l'etapa autonòmica" 15) ha apuntat com, a partir de les primeries del 2000, les noves migracions van 
fer entrar la sociolingüística en "un canvi d'etapa i de marc de referència" que ell anomena "la sociolingüística del multilingüisme". La recerca generada en aquest àmbit ha donat lloc a treballs relacionats amb els coneixements i usos lingüístics de la població al·lòctona, les actituds lingüístiques, el sentiment identitari o els processos d'acollida de la població immigrada per part de les poblacions autòctones. ${ }^{2}$ En definitiva, a investigacions dedicades a l'anàlisi dels factors relacionats amb el multilingüisme, ja sigui pel que afecta el comportament del parlant $\mathrm{o}$ els entorns en què conviu.

Un d'aquests entorns, l'educatiu en sentit ampli, ha generat importants línies d'investigació en el que s'ha anomenat sociolingüistica educativa (vegeu Vila, "La recerca sociolingüística"). No podem deixar de banda tampoc que parlar de multilingüisme en l'entorn escolar implica sovint analitzar el procés d'adquisició i d'aprenentatge lingüístics d'una llengua forana (LF) i els resultats productius que se'n deriven, així com els factors interns (relacionats amb el propi aprenent: edat, sexe, llengua materna, aptitud, actitud, etc.) i externs (vinculats a l'entorn d'aprenentatge o d'ús lingüístic: llengües que es parlen en l'entorn més proper, tipus d'aprenentatge formal en l'àmbit escolar, consum lingüístic (mitjans de comunicació, Internet, música ...), etc.) que s'hi relacionen. Precisament en aquesta línia se situa el treball que presentem.

\subsection{Anàlisi de la producció de parlants plurilingües}

\subsubsection{Adquisició d'una L2 o L3: la llengua catalana}

Un dels temes de debat de la recerca actual sobre els parlants poliglotes és com es produeix el procés d'adquisició d'una L2 o d'una L3/Ln, considerant aquesta darrera com a qualsevol llengua (L4, L5 ...) que s'adquireix després d'una segona. La història dels estudis a l'entorn de l'aprenentatge de segones llengües (vegeu, per exemple, la síntesi que en fa Comajoan, "Adquisició") demostra que no sempre s'ha donat resposta en el mateix sentit quant a la influència de la llengua materna de l'aprenent. A partir dels anys vuitanta, tanmateix, podem afirmar que es generalitza la idea que, efectivament, s'estableix una relació entre llengua materna i qualsevol de les altres llengües que s'aprenen; es tracta, però, d'una relació bidireccional. Des del punt de vista teòric, es redimensiona el concepte de transferència (Odlin; Kecskes i Papp) i es parla ja d'influència interlingüística (Jarvis i Pavlenko) o interdependència lingüística (Cummins). Es considera que el coneixement que una persona té d'una llengua influencia el coneixement d'una altra, perquè existeixen processos mentals subjacents comuns a l'aprenentatge d'una llengua materna i una d'estrangera. El model de multicompetència de Cook ("Evidence") es fonamenta en aquest supòsit, ja que defensa que tant les L1 com qualsevol altra llengua que no sigui la L1 poden tenir a veure amb l'aprenentatge d'una nova llengua. D'aquí que diversos estudis hagin explorat 
l'adquisició de llengües addicionals (L4, L5 ...) (Fouser) o els efectes que tenen la L2 o fins i tot la L3 sobre una L1 (Cook, Effects; Ringbom, "Lexical”). S'obre un interrogant, doncs, sobre com l'estructura gramatical d'una llengua influencia sobre una altra apresa amb posterioritat. En realitat es tracta de poder trobar el model més adequat de competència bilingüe, així com analitzar la permeabilitat o impermeabilitat dels diferents nivells gramaticals (fonètic, morfològic, lèxic i sintàctic) en el contacte de llengües (Silva-Corvalán 271).

Si ens fixem en el nivell fonètic - molt més permeable per exemple que el nivell sintàctic - , i ens centrem en la relació L1-L2 (o L3), diversos estudis confirmen que se sol produir una transferència de la primera o la segona cap al sistema fonològic de la llengua que s'aprèn (vegeu Cabrelli). Les dificultats perceptives i productives que s'observen a l'hora d'aprendre els sons d'una L2, tanmateix, no només vénen causades per les propietats fonètiques dels sons particulars d'una L1 sinó per l'estructura del sistema fonolòic, de manera que són tots els trets fonètics de la L1 i les distàncies entre els sons que conformen el sistema, els que influeixen en la producció i percepció d'una L2 (Brown). Cal tenir en compte també que, com més diferències hi ha entre un so de la L1 i un de la L2, més fàcilment es distingiran (i es produiran) els trets específics de la L2 (Flege). Per contra, les diferències mínimes sovint es passen per alt i, per tant, la transferència fonètica es manté (Major).

Encara parlant de sistemes fonològics, i si tenim en compte les hipòtesis generals que han explicat l'organització dels sistemes vocàlics, hi ha dues propostes: els models basats en la noció de dispersió (vegeu Lindblom) i els models quàntics, basats en l'existència de regions de gran estabilitat acústica ${ }^{3}$ (vegeu Stevens). En aquestes regions més estables se situarien les vocals més freqüents dels inventaris vocàlics (i.e. vocals altes ([i], [u]) i baixes [a]) i en altres zones més sensibles a les variacions articulatòries se situarien les vocals que es produeixen amb major precisió articulatòria i que, al mateix temps, apareixen amb menor freqüència. En el cas concret de les vocals mitjanes obertes del català, estudis que n'analitzen tant els aspectes productius (vegeu, per exemple, Carrera-Sabaté i Fernández-Planas; Recasens i Espinosa) com perceptius (Mora, Keidel i Flege; Sebastián-Gallés i Díaz; Sebastián-Gallés, Echeverría i Bosch), coincideixen a assenyalar més inestabilitat en les vocals $[\varepsilon] \mathrm{i}[\mathrm{\rho}]$ que en les extremes (com ara [i a u $]$ ). A més a més, des d'un punt de vista més general i comparant sistemes vocàlics de llengües diverses, la presència de dos graus d'obertura en les vocals mitjanes és menys freqüent que la presència d'un grau d'obertura (Maddieson). Tal com assenyala Amengual, les vocals mitjanes del català són més marcades (tipològicament menys preferides) i, en definitiva, més vulnerables a seguir la influència d'altres llengües que només tenen un grau d'obertura (com en castellà i romanès, el cas que ens ocupa i que veurem més endavant contrastats). 


\subsubsection{Variació social i complexitat lingüística en contextos multilingües}

A banda dels aspectes tipològics, la recerca vinculada a l'adquisició de llengües diferents ha apuntat la influència de diversos factors com ara: la competència lingüística en les llengües implicades, els contextos comunicatius on s'utilitza la llengua (ús d'L1 i L2), el temps de residència en l'entorn sociolingüístic, l'edat dels parlants, l'aptitud, la motivació, la instrucció i pràctica de la L2, la llengua i la intensitat de l'input, el context d'aprenentatge, l'ordre d'adquisició de les llengües i els aspectes cognitius dels parlants (vegeu-ne una revisió a Major).

En l'àmbit de la sociofonètica, també s'han considerat recurrentment variables com l'edat o el gènere, que poden explicar tant processos de canvi en curs com de manteniment de variables. Tal com afirma Labov (Principles 367), "Women deviate less than men from linguistic norms when the deviations are overtly proscribed, but more than men when the deviations are not proscribed". Precisament, tenint en compte el gènere dels informants, s'han trobat diferències en les mesures dels formants vocàlics que estan relacionades no només amb el gènere sinó també amb l'edat dels parlants (Huber et al.). Els mecanismes d'hipercorrecció entre parlants de procedències socials diverses han explicat a bastament processos de variació lingüística (Labov, Sociolinguistic Patterns) i, en contextos multilingües, l'“ethnic hypercorrection", ${ }^{4} \mathrm{o}$ bé "principle of counter reaction" (vegeu Labov, Principles) s'ha explicat com una tendència que afecta les generacions més joves d'immigrants per tal d'integrar-se en la cultura d'acollida. També s'ha observat que les interaccions cara a cara juguen un paper molt important per tal que hi hagi acomodació lingüística, ${ }^{5}$ i en definitiva, canvis lingüístics (Trudgill); en aquest sentit, els mecanismes d'acomodació que els individus duen a terme en la construcció de les gramàtiques individuals poden explicar com es representa cognitivament el significat social de la variació lingüística (Celata i Calamai). I és que les gramàtiques no són fixes ni estàtiques, sinó que es veuen modelades per l'experiència de cada parlant-oient. Consegüentment, l'adquisició, estructuració, organització, variació i canvi lingüístic d'una llengua no són aspectes independents sinó facetes diferents d'un mateix sistema que és complex i que es va adaptant als usuaris, que interactuen els uns sobre els altres i que es comporten seguint mecanismes perceptius i també motivacions socials (vegeu Pierrehumbert).

\section{OBJECTIUS I HIPÒTESIS}

L'objectiu principal d'aquest treball és analitzar elements de la producció fonètica (pronúncia de segments vocàlics); els usos lingüístics (llengües que usen amb els interlocutors amb qui es relacionen habitualment (pare, mare, germans, amics, companys de classe, professors, veïns) o bé les que utilitzen en el consum de mitjans 
de comunicació, ús de noves tecnologies, música, etc.), i les valoracions (actituds) respecte a les llengües utilitzades per part d'un grup d'adolescents (alumnes d'ensenyament secundari) que parlen lleidatà, a més de castellà, i que tenen el romanès o el català com a L1. Els motius d'aquest treball es fonamenten en dos aspectes; un purament lingüístic i l'altre més aviat de tipus sociolingüístic, que està connectat amb usos i valoracions lingüístiques dels enquestats.

Des del punt de vista lingüístic, el contrast fonètic permet establir algunes diferències relatives a l'inventari vocàlic de les tres llengües. Cal tenir en compte que, si comparem l'inventari vocàlic del català i el del romanès, mentre que el primer disposa de vocals mitjanes obertes $[\varepsilon]$ i $[0]$, aquestes són totalment absents en el del romanès, igual que en espanyol. En aquest sentit l'inventari romanès és més proper a l'espanyol. Aquesta sembla la raó més plausible per la qual en treballs previs realitzats sobre les vocals tòniques (Carrera-Sabaté, "Vocals tòniques") es va constatar que les diferències acústiques se centraven bàsicament en els fonemes $/ \varepsilon / \mathrm{i}$ $/ \mathrm{J} /$, presents en català però no en romanès ni en espanyol (vegeu les figures 1, 2 i 3).

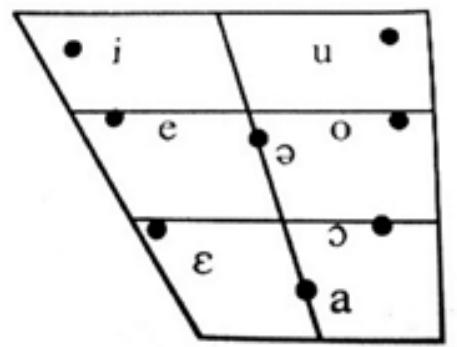

FIGURA 1. Inventari vocàlic de les vocals del català nord-occidental (adaptat de Carbonell i Llisterri)

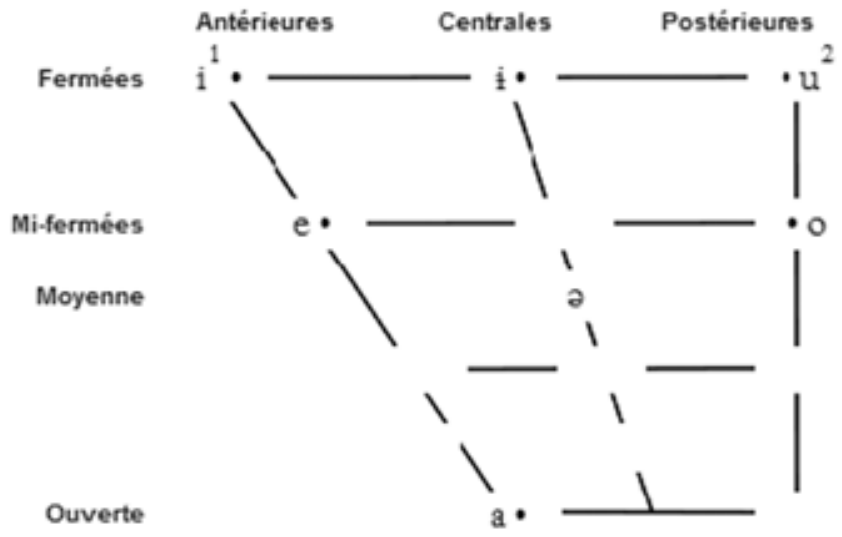

FIGURA 2. Inventari vocàlic de les vocals del romanès (Chiţoran) 


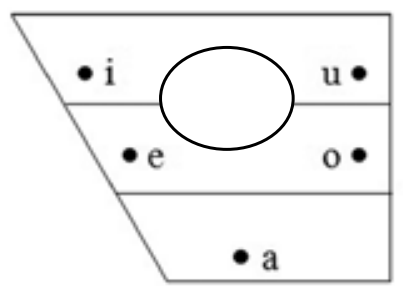

FIGURA 3. Inventari vocàlic de les vocals de l'espanyol (Martinez-Celdran, Fernández-Planas i Carrera-Sabaté)

Pel que fa a les motivacions sociolingüístiques, segons dades del padró municipal de la ciutat de Lleida del 2014 (vegeu Idescat), Romania ocupa la primera posició com a lloc de procedència de la població estrangera, en una xifra que s'apropa als 7.000 habitants i que suposa un 24,81\% del total de la població estrangera de la ciutat. De fet, un estudi publicat el 2010 sobre el mapa lingüístic de Lleida ja constatava aquesta tendència: "les llengües majoritàries parlades a la ciutat de Lleida, a més del català i del castellà, són les llengües provinents de l'Europa de l'Est. Es tracta d'un canvi significatiu respecte als resultats obtinguts el 2006, quan els parlants majoritaris a la capital del Segrià provenien d'Hispanoamèrica i, seguidament, dels països àrabs i berbers" (Lorés, Soto i Berenguer 98). Per tant, la mostra seleccionada d'informants, encara que limitada en nombre, creiem que és prou representativa de la realitat multilingüe lleidatana.

La conjunció d'aquesta doble motivació s'ha traslladat també al nivell metodològic com veurem més endavant. El que es pretén és analitzar els resultats productius a partir de la influència de variables socials (edat, sexe, anys de residència a Lleida, llengües d'ús amb l'entorn més immediat, etc.), els índexs de nivell competencial declarat vers les llengües que coneixen els informants (nivell corresponent a les llengües que parlen els informants segons la seva pròpia valoració) i el seu comportament en relació amb els usos lingüístics (actituds a l'hora de considerar la conveniència d'usar una llengua (català, castellà, romanès o anglès) (vegeu més endavant l'apartat de metodologia)).

Tenint en compte el que acabem de comentar, podem establir diferents hipòtesis de partida: 1 ) es preveuen diferències en la realització de les vocals $[\varepsilon] \mathrm{i}$ [o] en lleidatanoparlants que tenen diferents L1 (català i romanès) (vegeu CarreraSabaté, "North-western Catalan vowels"); 2) aquestes diferències poden veure's modificades per factors socials com el gènere, els anys de residència a Lleida i les llengües d’ús amb l'entorn més proper — família i amics — (vegeu Major); 3) els coneixements declarats sobre el nivell de la LE/LF (llengua estrangera o forana) en el cas dels alumnes romanesos, el català - té un impacte sobre la seva producció lingüística; 4) una actitud favorable vers aquesta LE — el català — sol ser una 
variable significativa a l'hora d'analitzar la producció lingüística dels parlants al·lòctons (Janés; Querol i Huguet; Querol).

\section{METODOLOGIA}

Per a dur a terme la nostra recerca hem partit d'una mostra de 27 adolescents, 15 dels quals tenen el romanès com a L1 ( 8 noies i 7 nois) i 12 amb el català com a L1 (6 noies i 6 nois). En ambdós casos es tracta d'alumnes d'ensenyament secundari que, en el moment de ser entrevistats, cursaven $2 \mathrm{n}$ i $4 \mathrm{t}$ d'ESO en dos centres de la ciutat de Lleida; ${ }^{6}$ per tant, ens movem en una forquilla d'edat entre els 13 i 18 anys.

Les tasques a què es van sotmetre els informants van ser les següents: a)

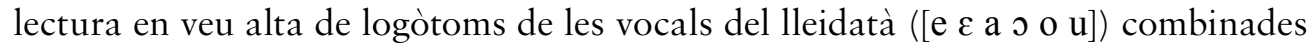
aleatòriament en contextos consonàntics simètrics [s_s / o_o $\left./ \int_{-} \int / \mathrm{k} \_\mathrm{k}\right] \mathrm{i}$ dins d'una frase portadora: "La Mar diu CVC quan vol" (ex. "la Mar diu sis quan vol") i b) lectura en veu alta d'un conte tradicional català. Les vocals que apareixen en tots dos contextos comunicatius no presenten totes la mateixa freqüència d'ús, cosa que també ocorre en la llengua natural (vegeu Rafel).

$\mathrm{Al}$ marge de les tasques, els informants van respondre uns qüestionaris escrits per tal d'obtenir les seves dades personals així com les relatives als seus coneixements, actituds i usos lingüístics. En aquest cas es va utilitzar un qüestionari sociolingüístic adaptat de l'emprat a Lasagabaster i Huguet, que a la vegada es basa en la proposta de Baker del 1992. Les 15 preguntes d'estructura tancada feien referència als aspectes següents: 1) dades personals (edat, sexe, estudis actuals i professió dels pares); 2) competència lingüística de diferents llengües, ${ }^{7}$ l'ús lingüístic i el consum lingüístic en diferents entorns i mitjans; ${ }^{8}$ 3) actituds lingüístiques i sentiments. ${ }^{9}$

Les variables lingüístiques que s'han tingut en compte són l'estructura formàntica de les vocals i la durada vocàlica. Per a l'anàlisi de les dades acústiques s'ha emprat el programa Praat i s'han normalitzat els formants seguint el mètode de Lobanov (Ferrari; Recasens). Igualment s'ha normalitzat la durada de les vocals proporcionalment a la durada de cada frase portadora i de cada unitat tonal. Per a la presentació de resultats s'han aplicat ANOVA multifactorial i d'un nivell. En total, s'han analitzat 700 vocals tòniques procedents de logòtoms llegits i 1.350 procedents de la lectura del conte.

Pel que fa a les variables socials que finalment s'han tingut en compte per la seva significació estadística han estat aquestes: la L1 (català, romanès), el gènere, els anys de residència a la ciutat de Lleida, les llengües d'ús de relació amb l'entorn més proper (concretament amb els amics) - no han resultat estadísticament significatius els resultats obtinguts segons altres entorns - la valoració pròpia (dades declarades) sobre els coneixements de català i els sentiments relacionats amb la llengua catalana. 


\section{RESULTATS I DISCUSSIÓ}

\subsection{Estructura formàntica i durada de vocals, $\mathrm{L} 1 \mathrm{i}$ gènere dels informants}

Una primera observació a les cartes formàntiques de les vocals normalitzades dels adolescents que tenen el català com a L1 i els que tenen el romanès com a L1 (vegeu els gràfics 1 i 2) permet determinar que, en els resultats de les dues tasques, les diferències entre les vocals del català en tots dos grups de parlants es troben en el primer formant de les vocals mitjanes, concretament, en les vocals [عe] i [əo]. En les dades provinents de la lectura del conte, també hi ha petites diferències en els segons formants de les vocals posteriors $[\mathrm{u}]$.

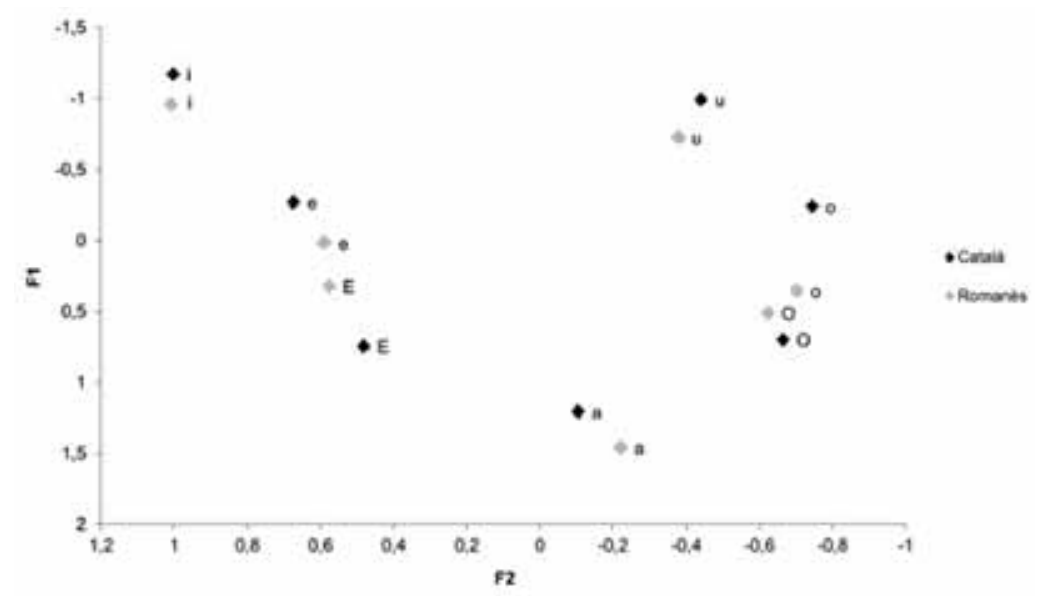

GRÀFIC 1. Carta de formants normalitzats dels resultats obtinguts en la lectura de logòtoms

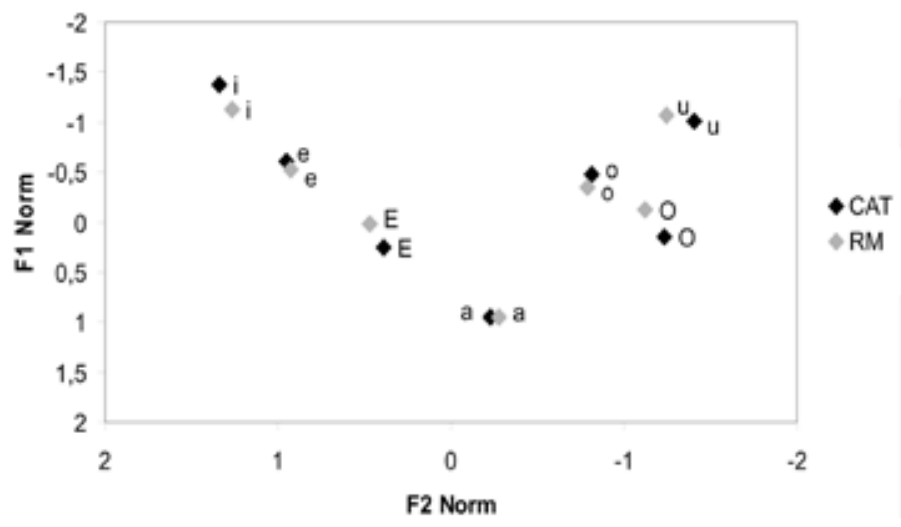

GRÀFIC 2. Carta de formants normalitzats dels resultats obtinguts en la lectura d'un conte 
Més concretament, s'observen diferències significatives en els valors d'F1 normalitzats de $[\varepsilon]$ i $[0]$, atès que en els parlants L1 català l'F1 és significativament més elevat (vegeu els gràfics 3 i 4).

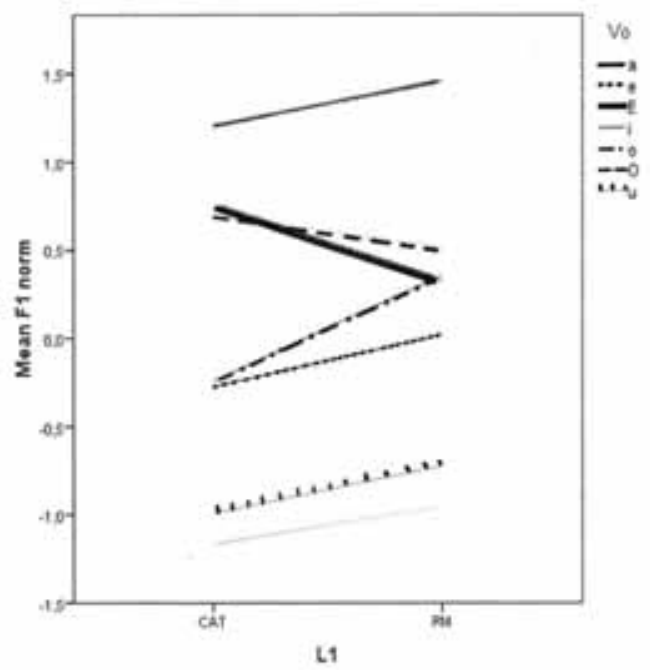

GRÀFIC 3. Valors d'F1 normalitzats segons la L1 dels enquestats (logòtoms) (F: 20,56// p: 0,0000)

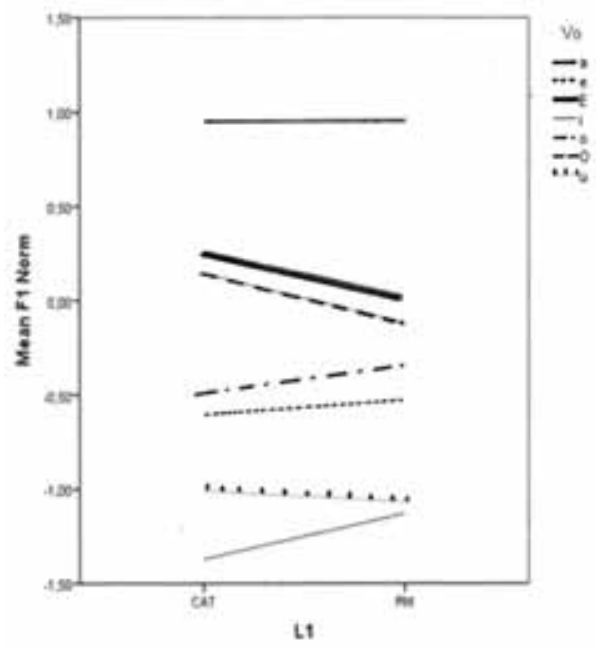

GRÀFIC 4. Valors d'F1 normalitzats segons la L1 dels enquestats (conte) (F: $12.93 / /$ p: 0.0000)

$\mathrm{Al}$ marge d'aquest aspecte, els parlants $\mathrm{L} 1$ català presenten distàncies més grans entre les vocals mitjanes obertes i tancades ([عe] i [oo]) que l'altre grup de parlants (vegeu els gràfics 5 i 6); relacionat amb això, l'F1 de [i a] i de [a u] són equidistants 
en tots dos grups, fet que es podria posar en relació amb la Quantal Theory of speech (Stevens), que defensa la presència de regions d'estabilitat en l'espai fonètic, les quals corresponen a les vocals extremes ([i a u $]$ ), vocals que, aproximadament tindrien la mateixa localització en totes les llengües, independentmet de la mida dels inventaris vocàlics. Endemés, tal com ja s'ha observat en altres recerques, les vocals mitjanes del català són menys marcades i, per tant, més inestables (vegeu Carrera-Sabaté i Fernández-Planas; Recasens i Espinosa; Amengual; etc.).

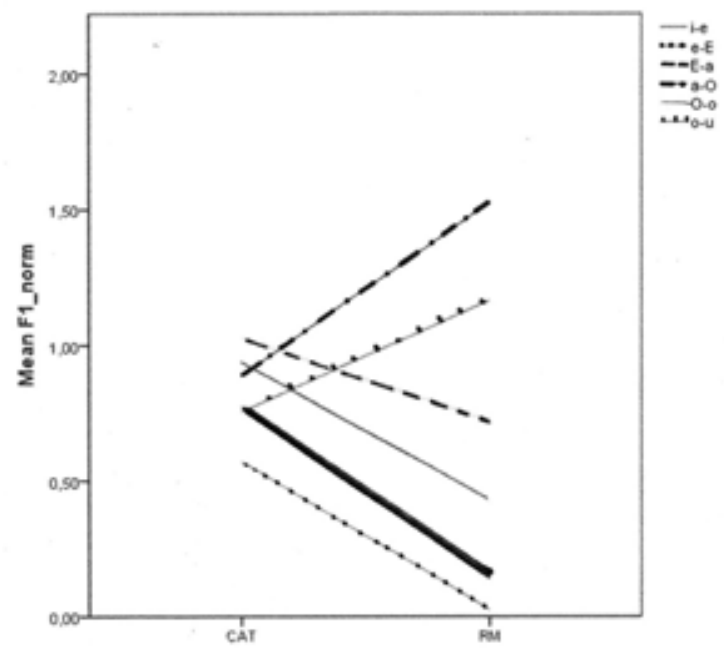

GRÀFIC 5. Distàncies dels valors d'F1 normalitzats segons la L1 dels enquestats (logòtoms) ([ $\varepsilon$-e]: $F=7,79 ; p=v a l=0,0099 ;[0-o]: F=12,36 ; p=0,0017)$

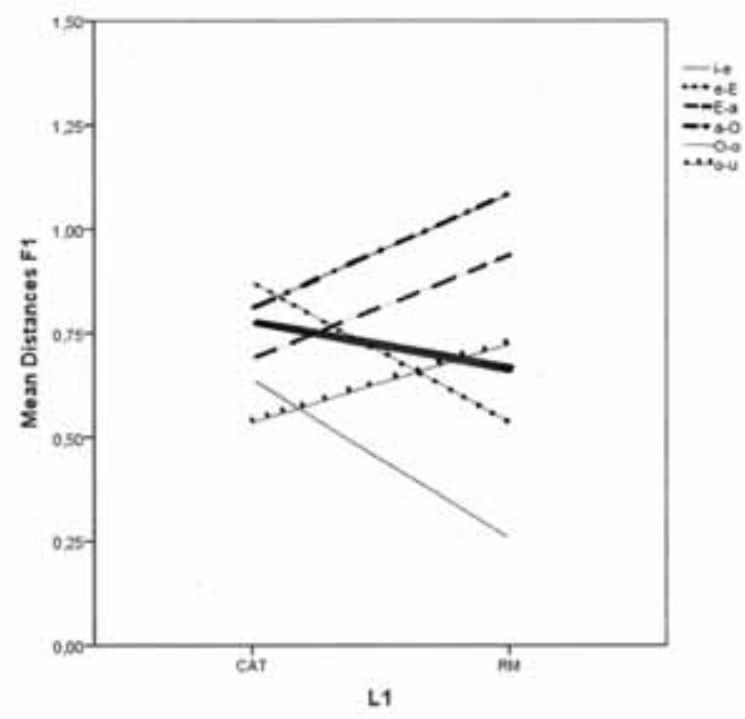

GRÀFIC 6. Distàncies dels valors d'F1 normalitzats segons la L1 dels enquestats (conte). ([ع-e]: $F=4,8 ; p=0,03 ;[0-o]: F=10,45 ; p=0,0034)$ 
Les vocals dels parlants L1 català són més curtes que les dels parlants L1 romanès (amb significació només en la lectura de logòtoms però amb una tendència similar a la lectura del conte; vegeu els gràfics 7 i 8). Pot ser que aquests resultats es puguin relacionar amb el tipus de tasca a què s'han sotmès els enquestats, atès que, tot i tenir fluïdesa i una competència elevada de català oral, aquesta llengua no és una L1, com en els altres enquestats.

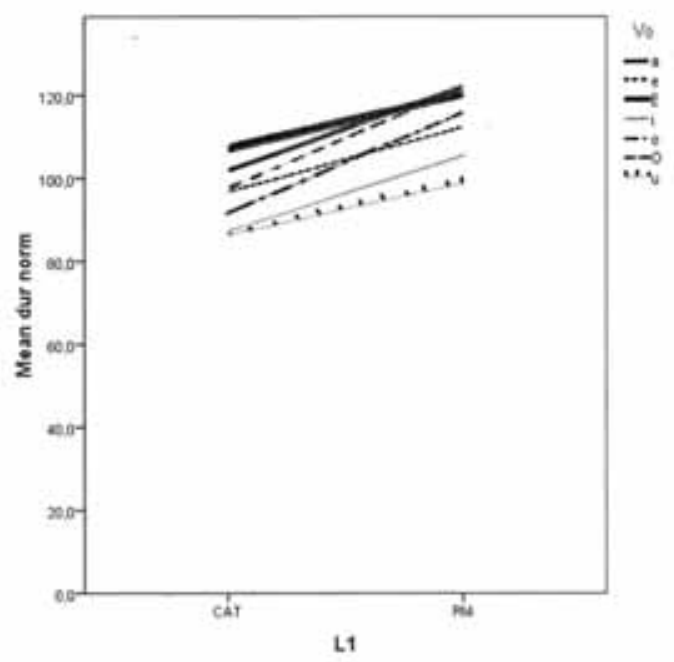

GRÀFIC 7. Durada de les vocals segons la L1 dels enquestats (logòtoms) (F: 83,02// p: 0,0000)

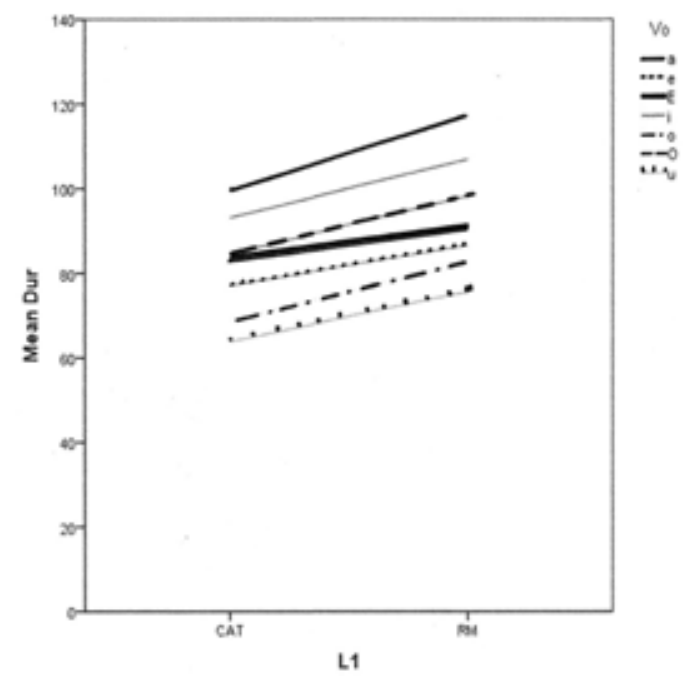

GRÀFIC 8. Durada de les vocals segons la L1 dels enquestats (conte) (F: $29.59 / /$ p: 0.0000) 
En les noies L1 català, $[\varepsilon]$ i [0] són les més obertes de tots els informants (en aquest cas les noies tindrien un paper més conservador, que permetria preservar les diferències més marcades de les vocals mitjanes). Els nois L1 romanès i català presenten un grau similar d'obertura en $[\varepsilon]$ i $[0]$ (vegeu els gràfics 9 i 10). Quant a les distàncies, els nois i les noies L1 català presenten una distància més llarga entre [عe] i [əo] comparats amb els L1 romanesos, per bé que els resultats no són significatius.

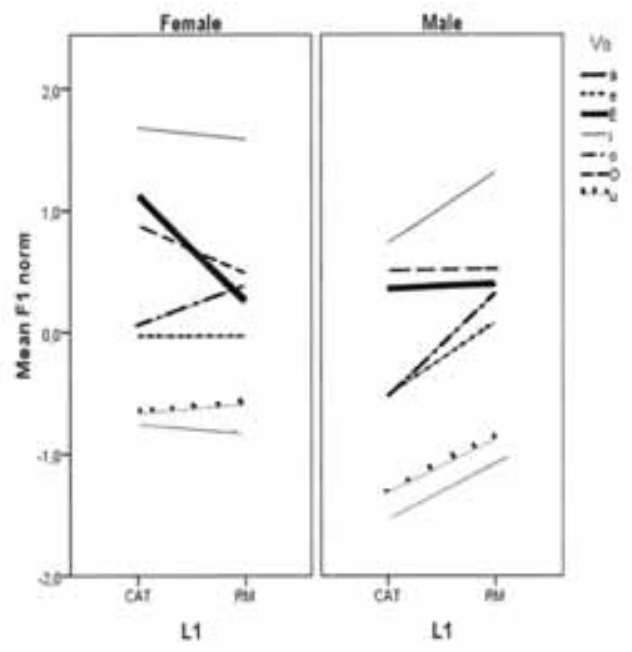

GRÀFIC 9. Valors d'F1 normalitzats segons la L1 i el gènere dels enquestats (logòtoms) (F: 5,30 // p: 0,0234)

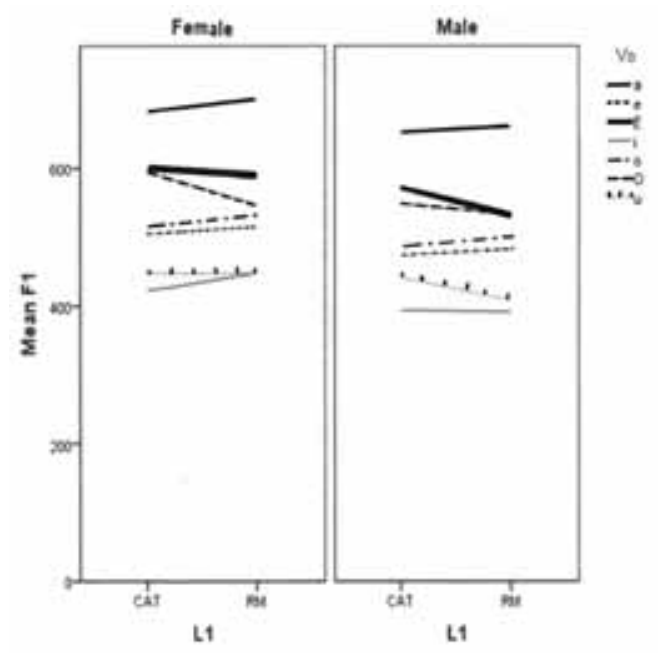

GRÀFIC 10. Valors d'F1 normalitzats segons la L1 i el gènere dels enquestats (conte) (F: 7,13// p: 0,0008) 


\subsection{Usos lingüístics dels parlants L1 romanès, caracterització social i vocals}

Els usos lingüístics en entorns familiars dels enquestats L1 romanès, és a dir, la comunicació que s'estableix entre pares i germans, confirma dues tendències importants. En primer lloc, s'observa un ús majoritari de la llengua romanesa, especialment amb els pares, alhora que s'utilitza també el castellà, però en percentatges poc rellevants. En segon lloc, es constata que, malgrat que aquesta llengua continua sent la dominant en la relació amb els germans, els percentatges es diversifiquen més; també ara el castellà és l'altra llengua més comuna de comunicació, però per primer cop apareix el català, encara que en percentatges baixos. És, doncs, en aquest sentit que es podria afirmar que els informants tenen com a L1 el romanès i que la seva L2 seria sobretot el castellà, si més no en l'entorn familiar (vegeu el gràfic 11).

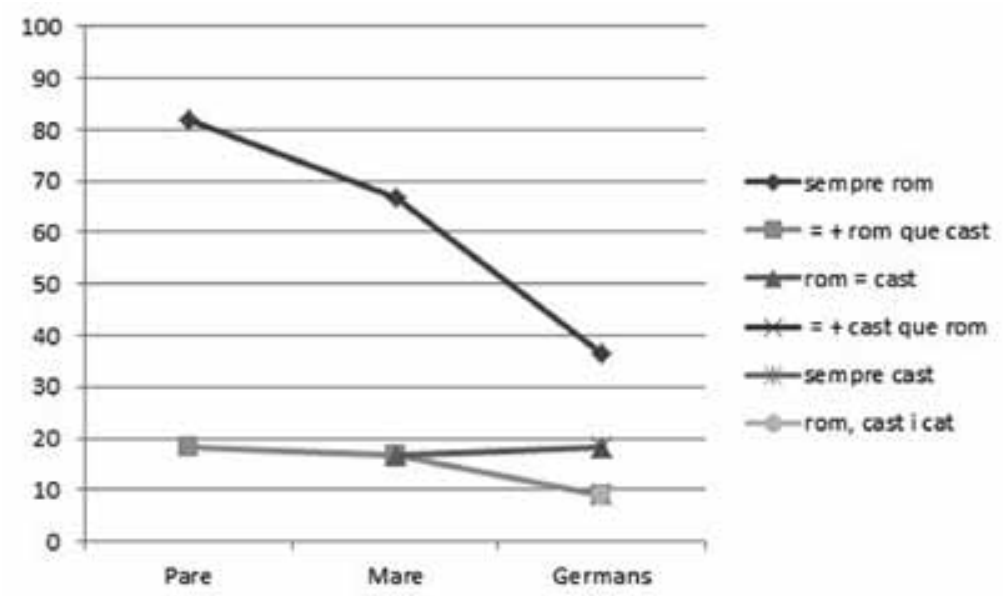

GRÀFIC 11. Usos lingüístics en l'entorn familiar

Aquests resultats coincideixen força amb els obtinguts en d'altres estudis realitzats en el marc educatiu català. Així, per exemple, en el treball de Comajoan et al., elaborat amb una mostra d'alumnes de sisè de primària d'escoles de diferents territoris catalans, ${ }^{10}$ es constata que els alumnes continuen emprant amb el pare i la mare la seva L1 (52). Tanmateix, en la relació amb els germans s'observen alguns canvis que tenen a veure amb l'ús d'altres llengües diferents de la L1, la qual continuen utilitzant - encara que en el nostre cas en un percentatge força inferior. La tendència sembla ser que l'ús del català augmenta en la relació amb els germans, pràcticament en tots els territoris $\mathrm{i}$ en tots els grups malgrat l'origen geogràfic familiar (56). De fet, l'anàlisi estadística assenyala que aquest origen geogràfic familiar és més important a l'hora d'explicar el major o menor ús del català amb els interlocutors que no pas el lloc de residència (55). 
Les mostres dades relatives als usos amb pares i germans contrasten, tanmateix, amb les relatives a les llengües que s'empren en l'àmbit escolar (l'institut). Òbviament aquí els percentatges majoritaris corresponen al català, sobretot en la relació amb els professors. En qualsevol cas, també s'utilitza la llengua castellana en percentatges baixos (entre 15\% i 25\%) i especialment en l'entorn de l'aula, la qual cosa inclou la relació amb els companys (vegeu el gràfic 12).

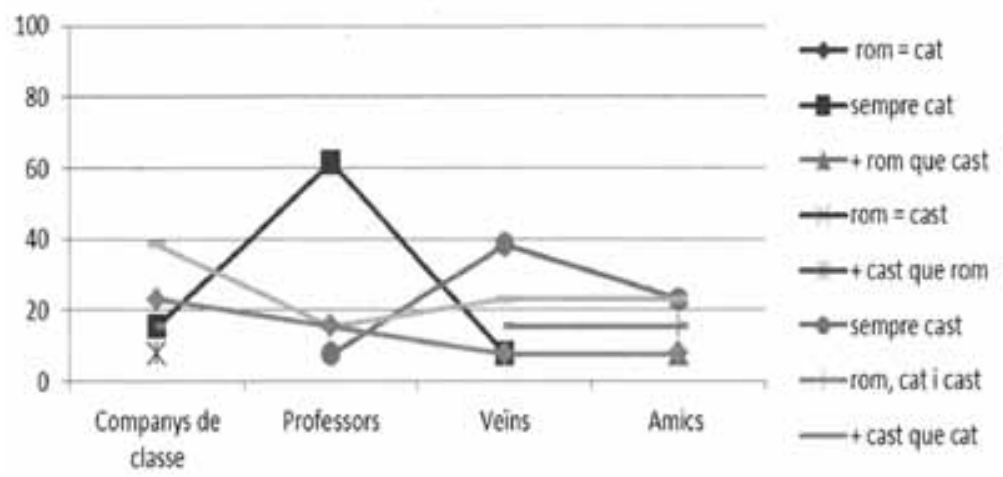

GRÀFIC 12. Usos lingüístics en l'àmbit escolar i l'entorn proper

La realitat lingüística que acabem de descriure és ben diferent de la que es crea en altres àmbits de relació com ara els veïns o els amics. D'una banda, es constata que la llengua més emprada torna a ser el castellà a la vegada que s'incorpora l'ús del romanès, però sempre en convivència amb el castellà; pel que fa al català, poc més del $7 \%$ afirmen usar-lo sempre de forma exclusiva, tot i que també és cert que de vegades s'alterna amb el castellà, en uns percentatges que se situarien en el $30 \%$. D'altra banda, s'observa una diversitat encara major en relació amb les llengües d'ús amb els amics, si més no en la distribució percentual, ja que igualment podem afirmar que s'usen les tres llengües: castellà, català i romanès. En aquest cas diríem que les dades relatives a les dues primeres llengües es mostren força equilibrades, mentre que l'ús del romanès indica que els informants mantenen relacions d'amistat $\mathrm{amb}$ altres romanesos. En els gràfics següents es pot visualitzar millor el contrast lingüístic entre català i castellà (gràfic 13) i el corresponent a romanès, català, castellà (gràfic 14). 


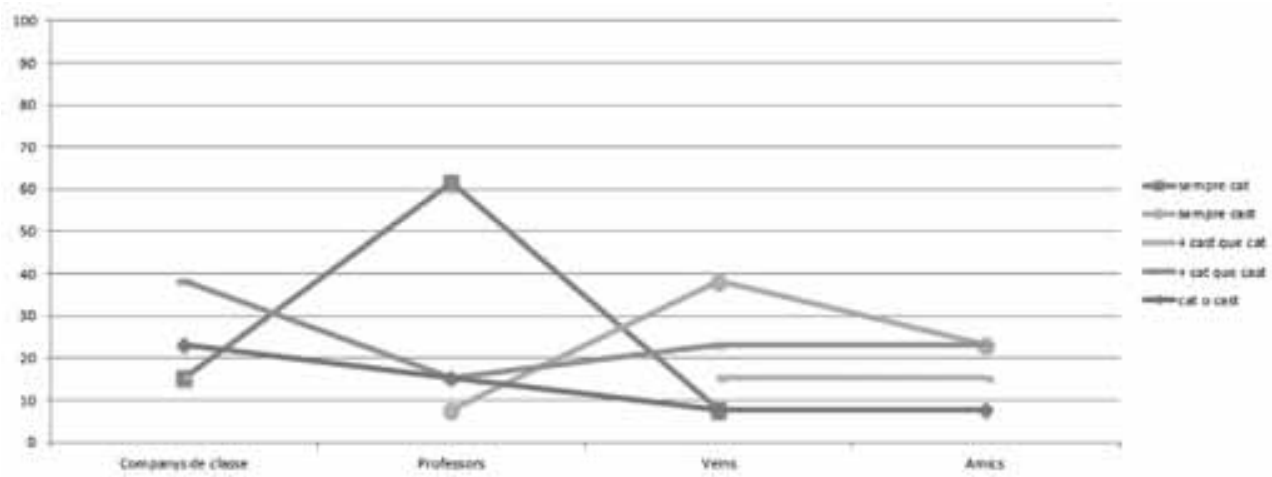

GRÀFIC 13. Contrast de l'ús del català i castellà en l'àmbit escolar i

l'entorn proper

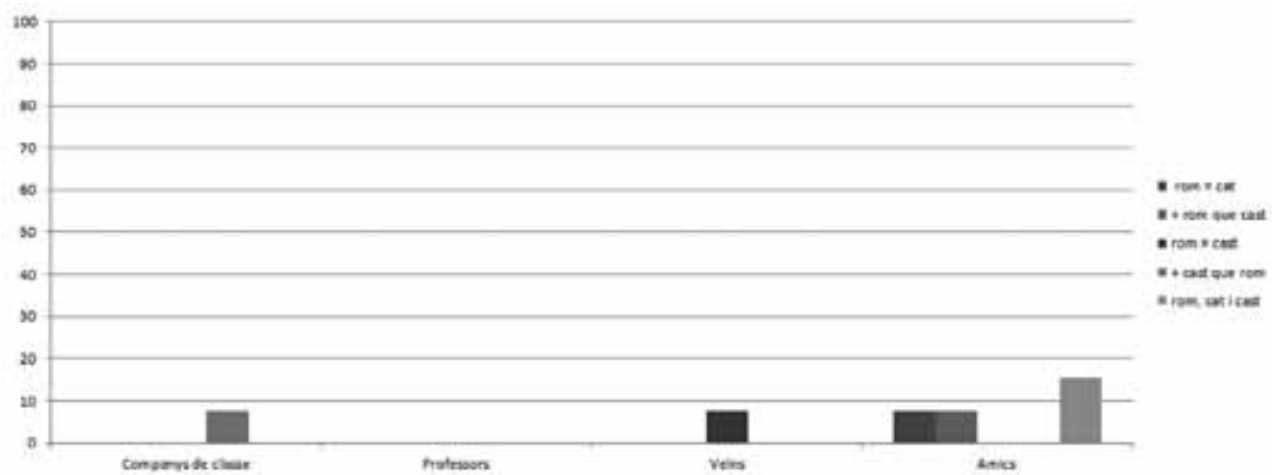

GRÀFIC 14. Contrast de l'ús del romanès, català i castellà en l'àmbit escolar i l'entorn proper

Pel que fa a les dades de la producció, ${ }^{11}$ en els informants L1 romanès, quan la llengua utilitzada amb els amics és el català (ailladament o juntament amb altres llengües), els valors d'F1 — és a dir, l'obertura — de les vocals $[\varepsilon]$ i $[0]$ tendeixen a ser més elevats que quan no s'utilitza aquesta llengua (vegeu els gràfics 15 i 16). ${ }^{12} \mathrm{~A}$ la vista d'aquesta tendència, en els informants L1 romanès que més utilitzen català hi ha un acostament a les realitzacions fòniques dels informants L1 català i, en aquest cas concret, els exemplars d'aquests parlants (en termes de Pierrehumbert) tendeixen a uniformitzar-se amb els que emeten els informants L1 català. Un cop més, l'ús de la llengua i la interacció cara a cara entre els parlants té un paper molt important en l'acomodació lingüística (Trudgill). Endemés, cal destacar que els valors d'F1 dels informants L1 romanès fins i tot poden arribar a ser més elevats que els observats en els enquestats L1 català, fet que podria explicar-se com un comportament proper a la hipercorrecció (vegeu Labov, Principles), entesa en la 
relació d'integració dels parlants al·lòctons (L1 romanès) al col-lectiu català. Pel que fa a la distància entre els formants de les vocals mitjanes [e $/ / \mathbf{o o}$ ], no s'observen diferències significatives quan l'ús de les llengües amb els amics varia.
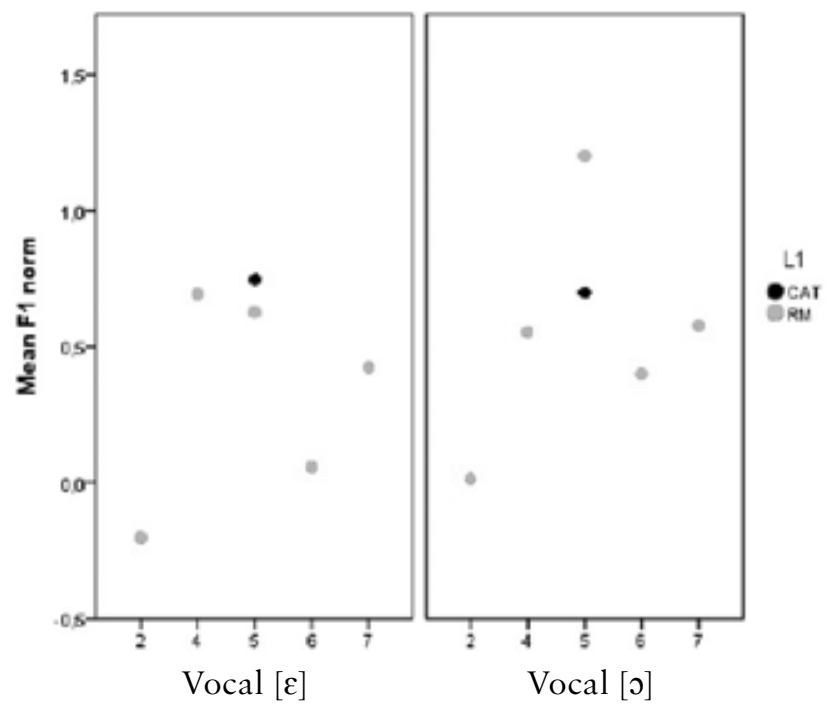

GRÀFIC 15. Valors d'F1 normalitzats segons la L1 dels enquestats i la llengua utilitzada amb els amics (logòtoms) ([0]: $\mathrm{F}=3,40 / / \mathrm{p}=0.04$ )

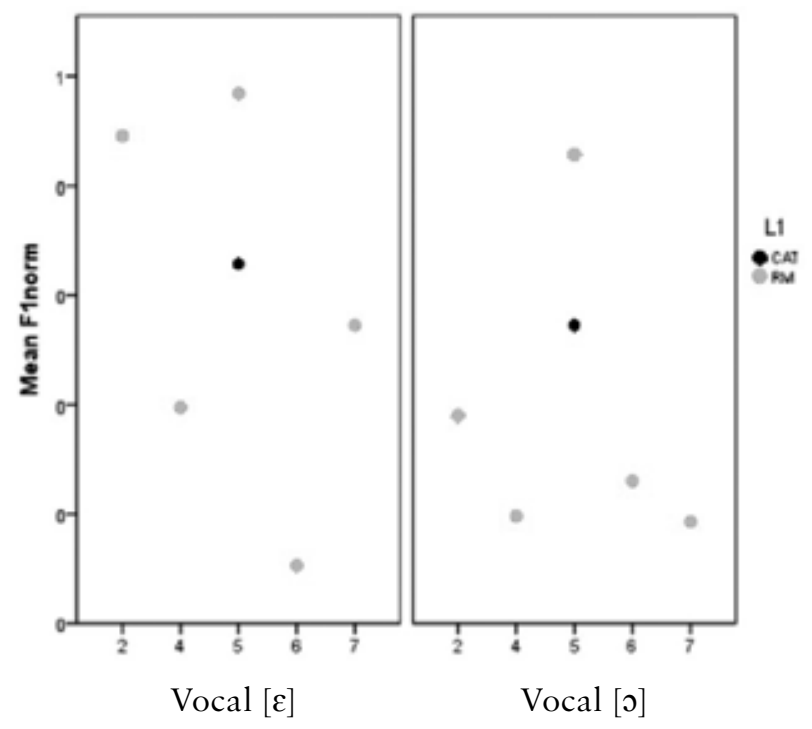

GRÀFIC 16. Valors d'F1 normalitzats segons la L1 dels enquestats i la llengua utilitzada amb els amics (conte) $([\varepsilon]: F=12.02 / / p=0.0000 ;[0]: F=11.94 / / p=0.0000))$

1: llengua dels pares, 2: llengua dels pares i català, 3: llengua dels pares i espanyol, 4: llengua dels pares i català i espanyol, 5: català, 6: espanyol, 7: català i espanyol 
Quant a la durada de les vocals, només s'observen diferències significatives relacionades amb la llengua d'ús amb els amics en la tasca de la lectura de logòtoms en frases portadores, tal com hem destacat anteriorment. En aquest cas, les vocals tendeixen a ser significativament més breus quan el català és la llengua que s'utilitza per a la comunicació amb els amics (vegeu el gràfic 17).

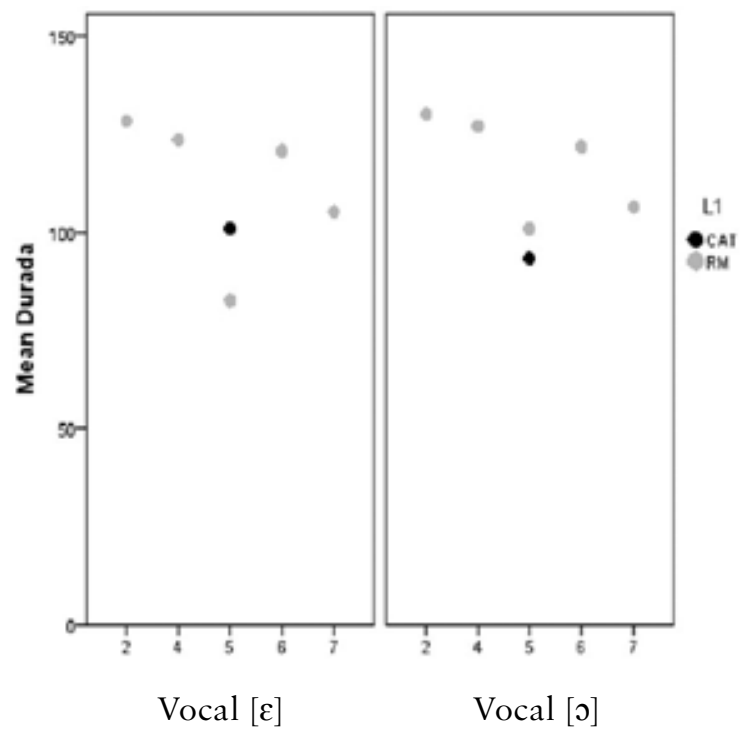

GRÀFIC 17. Valors d'F1 normalitzats segons la L1 dels enquestats i la llengua utilitzada amb els amics (logòtoms) ([ع]: $\mathrm{F}=2.12 / / \mathrm{p}=0.0093 ;[\mathrm{o}]: \mathrm{F}=2,76 / / \mathrm{p}=0.0382$ ) 1: llengua dels pares, 2: llengua dels pares i català, 3: llengua dels pares i espanyol, 4: llengua dels pares i català i espanyol, 5: català, 6: espanyol, 7: català i espanyol

\subsection{Valoracions lingüístiques, vocals i caracterització social}

Al marge d'aquests aspectes, i ara en relació amb la competència lingüística que els mateixos informants L1 romanès valoren pel que fa a les diferents llengües - parlem, doncs, de dades declarades —, es constata que, tot i tenir la llengua romanesa com a L1, els informants valoren la seva competència lingüística en aquesta llengua entre regular i bé. Quant a les tres llengües foranes comparades, qualifiquen els seus coneixements lingüístics generals en un $75 \%$ aproximadament de "bons" en el cas de l'anglès i "molt bons" en el cas del castellà i català (vegeu la gràific 18). 


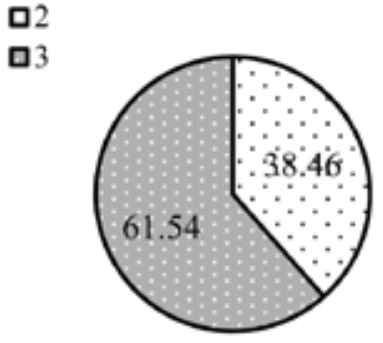

Coneixements generals romanès

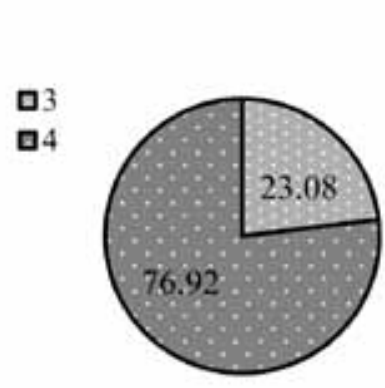

Coneixements generals castellà

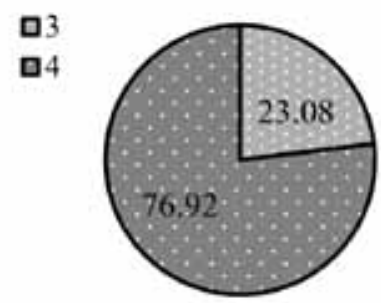

Coneixements generals català

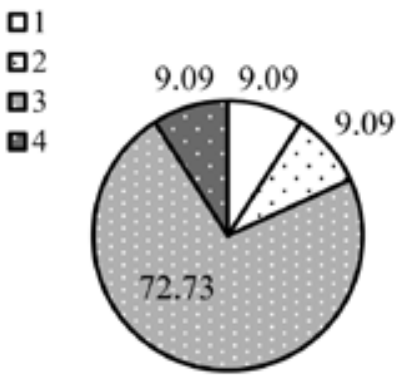

Coneixements generals anglès

GRÀFIC 18. Competència lingüística en romanès, català, castellà i anglès (llegenda: 1: gens, 2: regular, 3: bé, 4: molt bé)

Dels resultats obtinguts es desprenen algunes observacions. En primer lloc, en el cas del romanès recordem que és una llengua d'ús restringit als entorns que hem comentat en l'apartat anterior i que la valoració específica que en fan segons les quatre habilitats lingüístiques és força diferent (la més alta correspon a les habilitats orals). A més, la manca d'instrucció formal en romanès provoca que els seus coneixements avancin poc.

En relació amb les dades corresponents al català i al castellà, en principi, no ens ha de sorprendre la igualtat dels resultats, tot i que en l'anàlisi segons les habilitats lingüístiques es detecta alguna petita diferència. Cal tenir en compte que la majoria d'informants van començar a aprendre català i castellà de forma simultània i, majoritàriament, a partir dels 7-9 anys. Les petites diferències percentuals entre el castellà i el català creiem que s'expliquen per l'ús que es fa del castellà en l'entorn sociolingüístic immediat que, com ja hem dit, és una variable força important.

Si ens fixem ara en les dades obtingudes en les tasques orals dels enquestats s'observa que en les vocals mitjanes $[\varepsilon$ o $]$ de parlants L1 romanès l'F1 és més elevat com més coneixements de català afirmen que tenen els enquestats (vegeu els gràfics 18 i 19), però no segons els sentiments que els genera utilitzar una llengua determinada. 


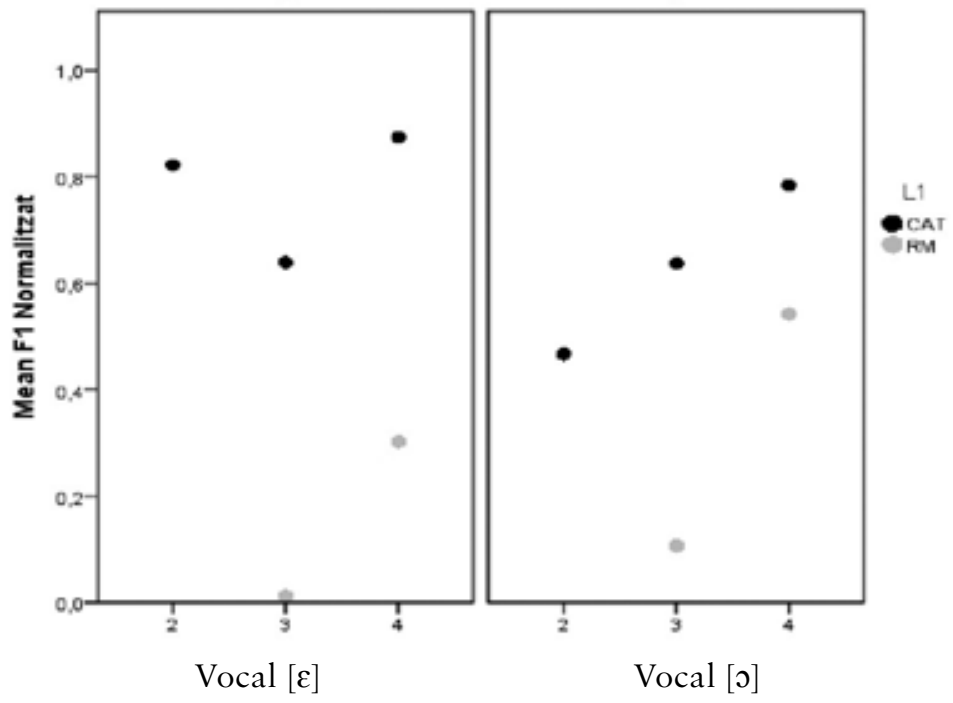

GRÀFIC 19. Valors d'F1 normalitzats segons la L1 dels enquestats i els coneixements declarats de català (logòtoms) $([\varepsilon]: F=5,84 / / p=0.0193 ;[0]: F=15,64 / / p=0.0002$ ) (llegenda: 1: gens, 2: regular, 3: be, 4: molt be)

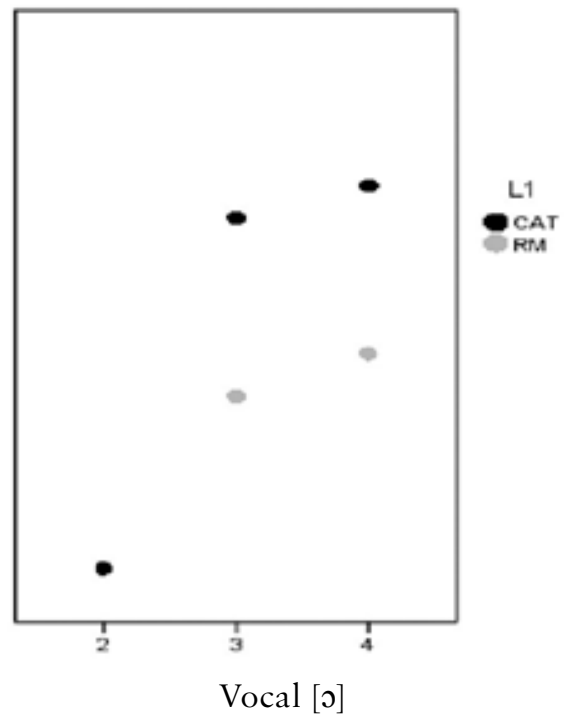

GRÀFIC 20. Valors d'F1 normalitzats segons la L1 dels enquestats i els coneixements declarats de català (conte) ([0]: $\mathrm{F}=3,89 / / \mathrm{p}=0.0233$ ) (llegenda: 1: gens, 2: regular, 3: bé, 4: molt bé) 


\section{OBSERVACIONS GENERALS: CONCLUSIONS}

Tal com assenyalàvem en els apartats introductoris, amb l'estudi que presentem es pretenia combinar l'anàlisi lingüística pròpiament dita, en el nostre cas de la producció fonètica de vocals mitjanes, amb la sociolingüística. Tot i que som conscients que partim d'una mostra de 27 informants, els resultats obtinguts ens permeten fer unes valoracions generals que podem prendre com a primeres conclusions.

La primera constatació és que les dades obtingudes evidencien diferències entre les vocals mitjanes $[\varepsilon]$ i $[0]$, obtingudes amb la lectura de logòtoms i d'un conte, emeses per dos grups de parlants, un amb L1 català i l'altre amb L1 romanès, la qual cosa confirma la primera de les hipòtesis plantejades. Les diferències en la pronunciació de $[\varepsilon]$ i $[0]$ es troben en 1 ) el grau d'obertura d'aquestes vocals (F1), ja que les vocals emeses per parlants amb L1 català són les més obertes; 2) les distàncies entre l'F1 de les parelles [e $\varepsilon]$ i $[o$ o], que en els parlants amb L1 català són més grans que en les dels romanesos; 3) la durada de les vocals, que solen ser més curtes en els parlants L1 català. Aquestes diferències es poden explicar per diversos motius que tenen a veure amb el contrast tipològic entre el català $i$ el romanès, $i$ d'altres variables relatives a factors socials, usos lingüístics i nivell competencial de les llengües implicades.

En relació amb les diferències tipològiques, com ja havíem avançat, les vocals del sistema fonològic del romanès són diferents de les del català perquè no tenen les vocals $/ \varepsilon / \mathrm{i} / \mathrm{\rho}$. A més a més, ens sembla important assenyalar que els parlants L1 romanès es troben en contacte permanent amb una altra llengua: l'espanyol, que tampoc no compta amb els fonemes $/ \varepsilon / \mathrm{i} / \mathrm{\jmath} /$, fet que pot afavorir la transferència al català no només de la L1 d'aquests parlants sinó d'una L2 que, en la majoria dels casos, és l'espanyol.

Quant a les variables socials que han evidenciat resultats més rellevants cal referir-nos a la variable gènere. Així les noies i els nois enquestats presenten actuacions diferenciades segons cada L1, seguint els postulats de la literatura variacionista (les noies amb L1 català presenten F1 més elevats). En canvi, han donat resultats desiguals altres variables com els anys de residència a la ciutat de Lleida o el contacte amb parlants autòctons catalans; amb aquesta observació es confirmaria parcialment la segona de les hipòtesis que plantejàvem prèviament. En el primer cas, les dades no han estat significatives, mentre que en el segon s'ha comprovat que el contacte amb la llengua catalana és important en els adolescents que tenen el romanès com a L1 i que usen el català amb els amics, tant si és per acomodació lingüística (vegeu Trudgill) com si és per "ethnic hypercorrection" (Labov, Principles). Aquests emeten les vocals $[\varepsilon]$ i [0] amb un F1 més elevat (més obertes) que els altres, tot i que no s'observen canvis que afectin la durada vocàlica. 
Podríem afirmar, doncs, que les vocals es van modificant en la mateixa direcció que les dels L1 catalans, quan el contacte amb aquests és més regular.

Finalment, el nivell de coneixements lingüístics en català segons valoracions declarades - no observades - per part dels informants mostra diferències significatives en l'F1 dels romanesos però no hi ha diferències en la durada de les vocals. Sembla que es confirmaria, doncs, que el major nivell competencial declarat de la LF té un impacte sobre la producció, tal com formulàvem en la tercera hipòtesi. Tanmateix, les nostres dades no avalen la consideració que una actitud favorable vers aquesta llengua tingui la mateixa repercussió. En aquest cas, no podem ratificar els postulats de la quarta hipòtesi.

Aquestes observacions, doncs, ens condueixen, un cop més, a valorar la llengua com un sistema complex que contínuament es modifica segons les situacions en què es troben els parlants (Pierrehumbert).

JOSEFINA CARRERA-SABATÉ

Universitat de Barcelona

IMMA CREUS

Universitat de Lleida

\section{NOTES}

1 Aquest treball és una versió ampliada i revisada de la comunicació que es va presentar l'1 de juliol de 2015 a l'Institut d'Estudis Catalans (Barcelona) en el marc del 15è Col-loqui Internacional de la North American Catalan Society. Aquesta recerca s'ha beneficiat d'un ajut del Grup d'estudi de la variació (Universitat de Barcelona (UB)).

2 Sense pretendre ser exhaustius, es pot veure un tast d'algunes d'aquestes tendències al volum editat per Vila i Salvat.

3 Serien les zones del tracte vocàlic en què les modificacions articulatòries no comporten grans diferències acústiques.

4 Es tracta d'un fenomen que consisteix en el fet que alguns parlants empren una característica associada amb el seu grup ètnic, fins i tot amb menys freqüència que els que no pertanyen a aquest grup.

5 En termes de la teoria establerta per Giles ens referim a aquelles situacions en què els individus adapten la seva forma de parlar assemblant-se als seus interlocutors (forma convergent) o diferenciant-se'n (divergent).

6 Agraïm a les professores Celi Canyadell i Gemma Mirmí dels centres d'educació secundària Episcopal i Joan Oró de Lleida, respectivament, la seva colllaboració i predisposició a l'hora de poder realitzar les enquestes als alumnes seleccionats. També agraïm la bona disposició dels estudiants enquestats.

7 En aquest cas es demanava als informants que valoressin la seva competència lingüística en diferents llengües (romanès, català, castellà, anglès) segons les diferents 
habilitats (llegir, escriure, parlar, escoltar i coneixements generals) i a partir d'una escala gradual d'1 a 4 (1: gens, 2: regular, 3: bé, 4: molt bé). Es tracta de dades declarades perquè no se sotmetien a proves per verificar-les.

8 Es demanava sobre les llengües d'ús habitual al mirar la televisió, llegir premsa, escoltar música, escoltar ràdio, escriure al Facebook, Messenger, SMS, Whatsapp, consultar internet o parlar pel mòbil.

9 En aquest cas, per tal de mesurar el seu component actitudinal es demanava als informants que valoressin (és molt important / important / bastant important / gens important) la importància d'emprar les llengües que usen habitualment (romanès, català i castellà) segons diferents circumstàncies (fer amics, aconseguir feina, estar integrat a Lleida, anar a comprar, etc.). Igualment havien d'expressar el seu acord o desacord en determinats supòsits (m'agrada sentir (romanès, català, castellà), m’agrada parlar en (romanès, català, castellà), no m'importaria casar-me amb un parlant de (romanès, català, castellà), etc.). Per a l'apartat de "sentiments" havien d'expressar com se sentien en parlar les llengües esmentades (angoixat, nerviós, incòmode, bloquejat, desmotivat, segur, tranquil, satisfet, feliç).

10 Es tracta d'un total de 2.598 alumnes de Vic, la Noguera, Sant Just Desvern, Manlleu, Mataró, Mallorca, Sant Joan Despí, Franja (Baix Cinca i Llitera).

11 No han resultat significatius els anys de residència a la ciutat de Lleida.

12 No es pot dir el mateix en relació amb la llengua utilitzada amb els pares i a l'institut.

\section{REFERÈNCIES}

Amengual, Mark. "The perception and production of language-specific midvowel contrasts: Shifting the focus to the bilingual individual in early language input conditions". International Journal of Bilingualism (2014): 1-20. Versió electrònica: <http://ijb.sagepub.com/content/early/2014/08/12/1367006914544988>.

Baker, Colin. Attitudes and Language. Clevedon, Bristol, UK: Multilingual Matters, 1992.

Brown, Cyntia. "The interrelation between speech perception and phonological acquisition from infant to adult". Second Language Acquisition and Linguistic Therory. Ed. John Archibald. Oxford: Blackwell, 2000. 4-63.

Cabrelli Amaro, Jennifer. "L3 phonology: An understudied domain". Third Language Acquisition in Adulthood. Eds. Jennifer Cabrelli Amaro, Suzanne Flynn i Jason Rothman. Amsterdam: John Benjamins, 2012. 33-60.

Carbonell, Joan, i Joaquim Llisterri. "Catalan”. Handbook of the International Phonetic Association 62. Cambridge, UK: Cambridge University Press, 1999. 61-65.

Carrera-Sabaté, Josefina. "North-western Catalan vowels read aloud by multilingual adolescent speakers". Learning and Using Multiple Languages. Current Findings from Research on Multilinguism. Eds. Maria Pilar Safont Jordà i Laura Portolés Falomir. Newcastle, UK: Cambridge Scholars Publishing, 2015. 259-93.

—. "Vocals tòniques del lleidatà en entorns multilingües". Treballs de Sociolingüística Catalana 23 (2013): 117-32. <http://publicacions.iec.cat/repository/pdf/00000205/ 00000072.pdf>. 
Carrera-Sabaté, Josefina, i Ana Maria Fernández-Planas. Vocals mitjanes tòniques del català. Estudi contrastiu interdialectal. Barcelona: Horsori, 2005.

Celata, Chiara, i Silvia Calamai. "Sociophonetic perspectives on language variation". Advances in Sociophonetics. Eds. Chiara Celata i Silvia Calama. Amsterdam i Philadelphia: John Benjamins, 2014. 1-13.

Cenoz, Jasone. Towards Multilingual Education. Clevedon, Bristol, UK: Multilingual Matters, 2009.

Chițoran, Ioana. The Phonology of Romanian: A Constraint-Based Approach. Berlin i Nova York: Mouton de Gruyter, 2001.

Comajoan, Llorenç. "Adquisició de primeres i segones llengües: perspectiva històrica i qüestions actuals". Caplletra 35 (2003): 15-46.

-. "Multilingüisme i recerca a Catalunya". Recerca $i$ gestió del multilingüisme: Algunes propostes des d'Europa. Mehrsprachigkeitsforschung und Mehrsprachigkeitsmanagement: Europäische Ansichten. Eds. Pere Comellas i Conxita Lleó. Münster, Alemanya: Waxmann, 2010. 253-68.

Comajoan, Llorenç, et al. "Els usos lingüístics en família i amb amics de l'alumnat autòcton i allòcton de sisè de primària a Catalunya, Mallorca i la Franja”. Noves migracions $i$ llengües. Eds. F. Xavier Vila i Eulàlia Salvat. Barcelona: AEAU-UB, 2013. 29-76.

Cook, Vivian. Effects of theSsecond Language on the First. Clevedon, Bristol, UK: Multilingual Matters, 2003.

—. "Evidence for multicompetence". Language Learning 42 (1992): 557-91.

Cummins, James. "The cross-lingual dimension of language proficiency: Implications for bilingual education and the optimal age issue”. Tesol Quarterly 14.2 (1981): 175-87.

De Angelis, Gessica. Third or Additional Language Acquisition. Clevedon, Bristol, UK: Multilingual Matters, 2007.

Ferrari, Sandra. "Evaluation of vowel normalization procedures". Journal of the Acoustical Society of America 67.1 (1980): 253-61.

Flege, James E. "Second language speech learning: Theory, findings, and problems". Speech Perception and Linguistic Experience: Issues in Cross-language Research. Ed. Winifred Strange. Timonium, MD: York Press, 1995. 233-77.

Fouser, Robert. "Too close for comfort? Sociolinguistic transfer from Japanese into Korean as an L >3". Cross-Linguistic Influence in Third Language Acquisition: Psycholinguistic Perspectives. Eds. Jasone Cenoz, Britta Hufeisen, i Ulrike Jessner. Clevedon, Bristol, UK: Multilingual Matters, 2001. 149-69.

Franceschini, Rita, Daniela Zappatore i Cordula Nitsch. "Lexicon and the brain: What neurobiology has to say about languages". The Multilingual Lexicon. Eds. Jasone Cenoz, Britta Hufeisen, i Ulrike Jessner. Clevedon, Bristol, UK: Multilingual Matters, 2003. 153-66.

García-Mayo, María del Pilar. "Cognitive approaches to L3 acquisition”. International Journal of English Studies 12.1 (2012): 129-46.

Giles, Howard. "Accent mobility: A model and some data”. Anthropological Linguistics 15 (1973): 87-105.

Hoffman, Charlotte, i Jehannes Ytsma, eds. Trilingualism in Family, School and Community. Clevedon, Bristol, UK: Multilingual Matters, 2004.

Huber, Jessica E., et al. "Formants of children, women, and men: The effects of vocal 
intensity variation". Journal of the Acoustical Society of America 106.3 (1999): 1532-1542.

Idescat. Població estrangera per països. Generalitat de Catalunya: Institut d'Estadística de Catalunya. Lleida, 2014. <http://www.idescat.cat/poblacioestrangera/?res=e635\& $\mathrm{nac}=\mathrm{a} \& \mathrm{~b}=12>$.

Janés Carulla, Judit. Les actituds lingüístiques de l'alumnat d'origen immigrant a Catalunya. Una anàlisi d'algunes variables de l'àmbit escolar $i$ sociofamiliar. Tesi doctoral, Universitat de Lleida, 2006. <http://www.tdx.cat/handle/10803/8297>.

Jarvis, Scott, i Aneta Pavlenko. Crosslinguistic Influence in Language and Cognition. Nova York i Londres: Routledge, 2008.

Kecskes, Istvan, i Tünde Papp. Foreign Language and Mother Tongue. Mahwah, NJ: Erlbaum, 2000.

Labov, William. Principles of Linguistic Change. Vol. 2. Social Factors. Oxford: Blackwell, 2001.

-. Sociolinguistic Patterns. Philadelphia: University of Pennsylvania Press, 1972. Trad. com Modelos sociolingüísticos. Madrid: Cátedra, 1983.

Lasagabaster, David, i Àngel Huguet. "Introduction: A transnational study in European bilingual contexts". Multilinguilism in European Bilingual Contexts. Language Use and Attitudes. Eds. David Lasagabaster i Àngel Huguet. Clevedon, Bristol, UK: Multilingual Matters, 2007. 1-13.

Leung, Yan-kit Ingrid. Third Language Acquisition and Universal Grammar. Bristol, UK: Multilingual Matters, 2009.

Lindblom, Björn. "On the origin and purpose of discreteness and invariance in sound patterns". Invariance and Variability in Speech Processes. Eds. Joseph S. Perkell i Dennis H. Klatt. Hillsdale, MI: Lawrence Erlbaum, 1986. 493-510.

Lorés, Elisenda, Joana Soto, i Oriol Berenguer. Les altres llengües a Lleida. Mapa lingüístic de Lleida 2010. Lleida: Pagès Editors, 2010.

Maddieson, Ian. Patterns of Sounds. Cambridge, UK: Cambridge University Press, 1984.

Major, Roy C. "Transfer in second language phonology: A review". Phonology and Second Language Acquisition. Eds. Jette G. Hansen Edwards i Mary L. Zampini. Amsterdam: John Benjamins, 2008. 63-94.

Martınez-Celdrán, Eugenio, Ana M. Fernández-Planas, i Josefina Carrera-Sabaté. "Castilian Spanish". JIPA 33.2 (2003): 255-59.

Mora, Joan C., James L. Keidel, i James E. Flege. "Why are the Catalan contrasts between /e/-/ع/ and /o/-/o/ so difficult for even early Spanish-Catalan bilinguals to perceive?" Achievements and Perspectives in SLA of Speech: New Sounds, 2010. Eds. Magdalena Wrembel, Małgorzata Kul, i Katarzyna Dziubalska-Kołaczyk. Vol. 2. Frankfurt am Main, Alemanya: Peter Lang, 2011. 183-93.

Odlin, Terence. Language Transfer: Cross-linguistic Influence in Language Learning. Cambridge: Cambridge University Press, 1989.

Pierrehumbert, Janet B. "Exemplar dynamics: Word frequency, lenition, and contrast". Frequency and the Emergence of Linguistic Structure. Eds. Joan Bybee i Paul Hopper. Amsterdam: John Benjamins, 2001. 137-57.

Querol, Mònica. Relacions entre actituds i competències lingüístiques al final de l'Educació Secundària Obligatòria. El cas de l'alumnat d'origen immigrant a Catalunya. Tesi doctoral, Universitat de Lleida, 2011. <http://www.tdx.cat/handle/10803/80092>. 
Querol, Mònica, i Àngel Huguet. "Conocimiento lingüístico y actitudes lingüísticas. Un estudio sobre sus relaciones en el alumnado de origen inmigrante en Cataluña”. Segundas Lenguas \& Inmigración, Monográfico 1 (2010): 79-102.

Rafel, Joaquim. "Dades sobre la freqüència de les unitats fonològiques del català". Estudis universitaris catalans XXIV. Estudis de llengua i literatura catalanes oferts a R. Aramon i Serra en el seu setantè aniversari (2). Barcelona: Curial, 1980. 473-96.

Recasens, Daniel. "Mètodes de normalització i de representació de dades acústiques i articulatòries". Estudios de Fonética Experimental XVII (2008): 331-41.

Recasens, Daniel, i Aina Espinosa. "Dispersion and variability of Catalan vowels". Speech Communication 48 (2006): 645-66.

Ringbom, Hakan. "Lexical transfer in L3 production". Cross-linguistic Influence in Third Language Acquisition: Psycholinguistic Perspectives. Eds. Jasone Cenoz, Britta Hufeisen, i Ulrike Jessner. Clevedon, Bristol, UK: Multilingual Matters, 2001. 59-68.

Sebastián-Gallés, Núria, i Begoña Díaz "First and second language speech perception: Graded learning”. Language Learning 62 (2012): 131-47.

Sebastián-Gallés, Núria, Sagrario Echeverría, i Laura Bosch. "The influence of initial exposure on lexical representation: Comparing early and simultaneous bilinguals". Journal of Memory and Language 52 (2005): 240-55.

Silva-Corvalán, Carmen. Sociolingüistica y pragmática del español. Washington D.C.: Georgetown University Press, 2001.

Stevens, Kenneth N. “On the quantal nature of speech”. Journal of Phonetics 17.1/2 (1989): $3-45$.

Trudgill, Peter. "Contact and isolation in linguistic change". Language Change: Contributions to the Study of Its Causes. Eds. Leiv E. Earl Breivik i Ernst H. Jahr. Berlin: Mouton de Gruyter, 1989. 227-37.

Vila, F. Xavier. "De l'‘etapa autonòmica' a la 'sociolingüística del multilingüisme': una dècada de recerca sociolingüística sobre les noves immigracions”. Noves immigracions i llengües. Eds. Francesc X. Vila i Eulàlia Salvat. Barcelona: AEAU-UB, 2013. 11-28.

—. "La recerca sociolingüística educativa escolar als països de llengua catalana: elements per a un balanç". Treballs de Sociolingüística Catalana 21 (2011): 205-19. <http:// revistes.iec.cat/index.php/TSC/article/view/53862/pdf_128>.

Vila, Francesc X, i Eulàlia Salvat, eds. Noves immigracions i llengües. Barcelona: AEAUUB, 2013.

Wei, Li. "Research perspectives on bilingualism and multilingualism". The Blackwell Guide to Research Methods in Bilingualism and Multilingualism. Eds. Li Wei i Melissa G. Moyer. Oxford: Blackwell, 2008. 3-17. 